\title{
Exploring Environmental Reactions in "Real World" Materials using In Situ Analytical TEM
}

\author{
M.G. Burke ${ }^{1}$, A. Janssen ${ }^{1,2}$, M.L. Martin ${ }^{3}$, G. Bertali ${ }^{1}$, E. Prestat ${ }^{1}$, T. Woodward ${ }^{1}$, P. Sofronis ${ }^{4}$, and B. \\ Connolly ${ }^{1}$ \\ 1. Materials Performance Centre, The University of Manchester, Manchester, UK \\ 2. AkzoNobel Specialty Chemicals, Deventer, NL \\ 3. National Institute of Standards and Technology, Boulder, CO, USA \\ ${ }^{4}$ University of Illinois Urbana-Champaign, Urbana, IL, USA
}

Environment-sensitive behaviour of materials encompasses a broad range of degradation phenomena in metals and alloys. The interaction of metallic materials with the environment is of fundamental importance in understanding a material's performance in "real world" applications. Of particular significance is the effect of liquid and/or gaseous environments on the material of interest. The ability to visualize the localised changes associated with oxidation in gaseous environments and dissolution reactions in liquids coupled with qualitative STEM-XED spectrum imaging and analysis is now providing unprecedented opportunities for real-time observations that can lead to improved mechanistic understanding of nanoscale oxidation, and localised dissolution/corrosion, including the local electrochemical changes.

We have been applying several Protochips in situ platforms to examine both gaseous and liquid environmental interactions in structural alloys such as Ni-base alloys (Alloy 600) and steels. The Protochips Atmosphere system interfaced with an FEI Titan G2 200 kV S/TEM equipped with X-FEG and Super X (4 SDDs) has been successfully used in a variety of gaseous environments. Similarly, the Poseidon series of liquid and electrochemical holders permit the direct evaluation of electron-transparent alloys in a variety of liquids including acids and have been used successfully in a variety of analytical TEMs, including the FEI Talos F200 with the Super X multiple SDD configuration. Critical to any in situ experiment is the preparation of representative electron-transparent samples, so as to provide a valid link with bulk behaviour. Electron-transparent specimens were prepared using the hybrid method [2]. These specimens can then be attached to an Atmosphere heating chip with Pt, Figure 1, or to the specially-designed electrochemical chip (Protochips "Manchester" chip) for liquid or electrochemical experiments, Figure 2.

A series of examples will be discussed that are related to the detailed study of bulk material behaviour including localised oxidation reactions pertinent to stress corrosion cracking in Ni-base alloys as well as the detailed study of steels in liquid and gaseous environments. The successful experiments using the gas reaction cell system in a variety of $\mathrm{H}_{2}$-containing environments at elevated temperatures can be further refined to assess variables such as $\mathrm{H}_{2}$ and $\mathrm{O}_{2}$ partial pressures, and can also be used to assess localised reactions in 1 bar gas over a range of temperatures of interest and thus provide insight at the nanoscale about diffusion-induced grain boundary migration, internal oxidation, and the role of carbides in preferential oxidation. Similarly, the detailed ex situ and in situ electrochemical response of austenitic stainless steel in dilute acidic solutions with respect to both temperature and compositional variations will be discussed with respect to degradation phenomena.

References:

[1] N.J. Zaluzec, et al., Micros. Microanal., 20 (2014), p. 323.

[2] XL Zhong, et al., Micros. Microanal. 22 (2016), p. 1350.

[3] S. Schilling, et al., Micros. Microanal. 25 (2017), p. 741.

[4] G. Bertali, F. Scenini, and M.G. Burke, Corr. Sci. 100 (2015), p. 474.

[5] M.G. Burke, et al., Ultramicroscopy 176 (2017), p. 46. 


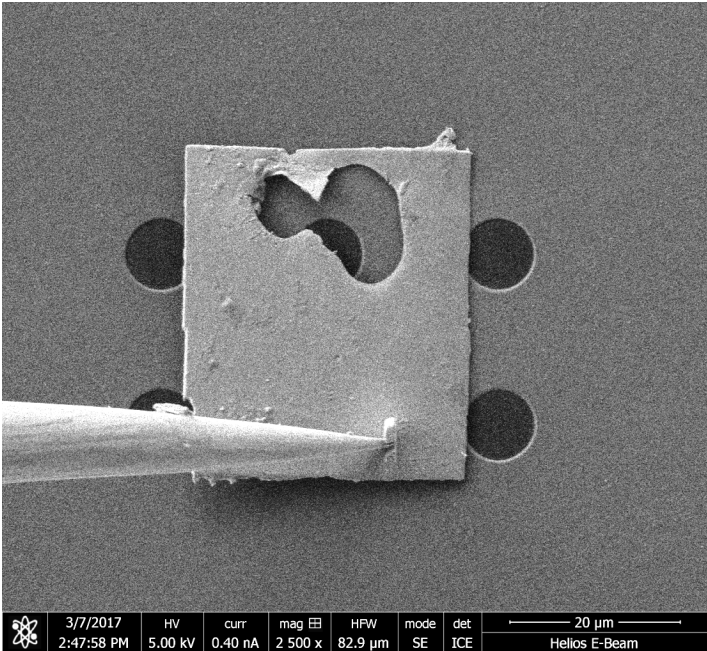

Figure 1. Secondary electron (SE) image of electron-transparent section extracted from an electropolished steel foil and placed on the heating chip for the Atmosphere holder.

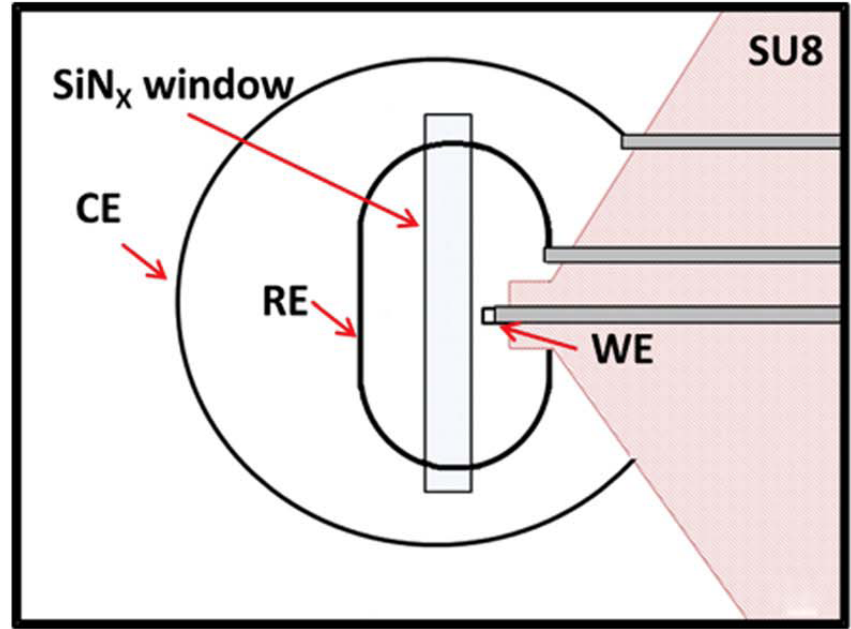

Figure 2. Schematic of modified electrochemical chip ("Manchester" chip). From [3].

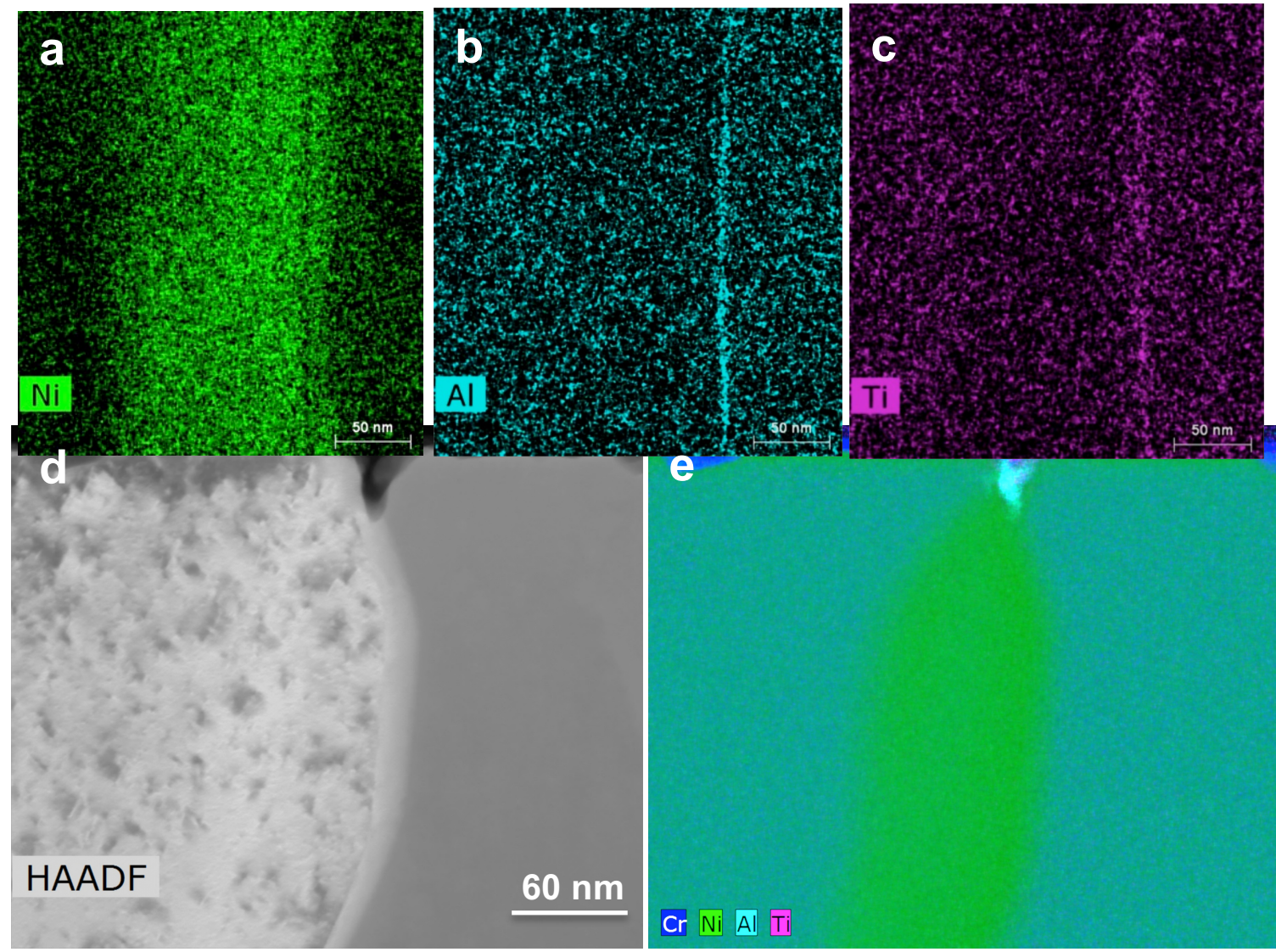

Figure 3. $26 \mathrm{~h}$ in situ oxidation at $400^{\circ} \mathrm{C}$ of a $300 \mathrm{~nm}$ thick Alloy 600 specimen in $\sim 1$ bar $\mathrm{H}_{2}-\mathrm{H}_{2} \mathrm{O}(\mathrm{v})$ under reducing conditions. Qualitative STEM-EDX maps for (a) Ni, (b) Al and (c) Ti acquired at $400^{\circ} \mathrm{C}$ and $\sim 1$ bar gas (cell gap $=5$ $\mu \mathrm{m})$. FIB-ed cross-section specimen prepared from the thick in situ sample: (d) STEM-HAADF image of the migrated boundary, and (e) corresponding composite Ni, Cr, Al, Ti EDX map showing the thin $\mathrm{Cr}_{2} \mathrm{O}_{3}$ surface oxide and $\mathrm{Al} / \mathrm{Ti}$ enrichments at the near-surface grain boundary, and the pronounced $\mathrm{Cr}$-depletion/Ni-enrichment in the migrated region. 